International Journal of Dentistry and Oral Science (JDOS)

ISSN: $2377-8075$

\title{
Comparison of Retention Forces of Different Fabrication Methods of Co-Cr Crowns: Pre-sintered and Milled, Cast and Electroforming Secondary Crowns with Different Taper Angles
}

Wagner $\mathrm{C}^{1}$, Stock $\mathrm{V}^{1}$, Merk $\mathrm{S}^{1}$, Schmidlin $\mathrm{PR}^{2}$, Roos $\mathrm{M}^{3}$, Eichberger $\mathrm{M}^{1}$, Stawarczyk $\mathrm{B}^{1 *}$

${ }^{1}$ Department of Prosthodontics, Dental School, Ludwig-Maximilians-University Munich, Germany.

${ }^{2}$ Clinic of Preventive Dentistry, Periodontology and Cariology, Center of Dental Medicine, University of Zurich, Switzerland.

${ }^{3}$ Department of Biostatistics, Epidemiology Biostatistics and Prevention Institute, University of Zurich, Switzerland.

\begin{abstract}
To investigate the retention forces of differently fabricated secondary crowns made of Co-Cr alloy and electroforming secondary crowns considering different taper angles. Cobalt-chromium primary crowns with $0^{\circ}, 1^{\circ}$ and $2^{\circ}$ taper angles were fabricated. Secondary crowns were made either by i.) a milling and sintering, ii.) casting or iii.) electro-forming process. Pull-off tests were performed and data were analyzed by parametric statistics $(p<0.05)$. With regard to the different taper angles, $\mathrm{Co}-\mathrm{Cr}$ milled and cast groups, no impact on retention force was observed. Within the electroforming group, primary crowns with a taper angle of $1^{\circ}$ showed a higher retention force than crowns with angles of $0^{\circ}$ or $2^{\circ}$. With respect to the secondary crowns, primary crowns with a taper angle of $1^{\circ}$ showed no impact on the results. Within the taper angles of $0^{\circ}$ and $2^{\circ}$, the electroforming group exhibited lower retention forces than cast or milled ones. In the $0^{\circ}$ taper angle group, milled secondary crowns displayed higher values than cast ones.
\end{abstract}

Keywords: Cobalt Chromium; Electroforming; Double Crowns; Retention Force; CAD/CAM.

\section{*Corresponding Author:}

Bogna Stawarczyk MSc,

Department of Prosthodontics, Dental School, Ludwig-Maximilians-

University Munich, Goethestrasse 70, 80336 Munich, Germany.

Tel: +4989440059573

Fax: +49 89440059502

E-mail: bogna.stawarczyk@med.uni-muenchen.de

Received: April 14, 2015

Accepted: May 21, 2015

Published: May 23, 2015

Citation: Stawarczyk B, et al., (2015) Comparison of Retention Forces of Different Fabrication Methods of Co-Cr Crowns: Pre-sintered and Milled, Cast and Electroforming Secondary Crowns with Different Taper Angles. Int J Dentistry Oral Sci. S2:003, 15-20. doi: http://dx.doi. org/10.19070/2377-8075-SI02003

Copyright: Stawarczyk $\mathbf{B}^{\mathcal{O}}$ 2015. This is an open-access article distributed under the terms of the Creative Commons Attribution License, which permits unrestricted use, distribution and reproduction in any medium, provided the original author and source are credited.

\section{Introduction}

Dental materials have tremendously evolved and future trends are continuously presented in the literature [1]. However, each new dental material is compared with proven materials, which have already been well-established over the past few years. Especially metal alloys belong to these long-time proven materials under which cobalt-chromium (Co-Cr) is entrenched [2] due to its mechanical strength [3] and high young's modulus [2]. With its high corrosion resistance [4] and its high biocompatibility [3, 5], Co$\mathrm{Cr}$ alloys are especially suitable for prosthodontic restorations [2].
This has been confirmed by many studies concerning the longevity of Co-Cr alloy showing no adverse reactions to the patients [5].

A few different fabrication methods, based on laser sintering [2], casting $[6,7]$ or milling [2] are known to produce prosthodontic made of Co-Cr alloys. The laser sintering process, a relatively new method bringing Co-Cr alloy into its final form, fuses together Co-Cr granules in layers by using a carbon dioxide laser beam [2]. This sustainable procedure impresses with its little material wear [2] but the costs and technical effort seem to be rather unprofitable for small dental companies [7] and is therefore in rare use. Casting Co-Cr alloy occurs with the traditional proven lost-wax technique [8] depending on technical skills and hand-made fitting [6], whereas the milling process allows using industrial prefabricated homogenous blanks [9]. In contrast to the casting process, the results yielded with milling are influenced by the design program and the milling settings of the computer-aided-design (CAD) and computer-aided-manufacturing (CAM) process [9]. To simplify the milling process of Co-Cr alloy, chalky blanks of alloy powder have been developed to get milled under dry conditions with smaller CAM machines to be sintered in a follow-up process. One of these chalky blanks has already been examined in regard to the fracture behavior of fixed dental prostheses (FDPs). It emerged that the Sintron frameworks, being CAD/CAM milled and sintered, were comparable to conventional casted frameworks [7].

Because of the proven fabrication method with lost-wax technique and the advantages mentioned above, Co-Cr alloy is established to be used for clasps [10], metal crowns [11], FDPs [4, 5] and removable dental prostheses (RDPs) [12-16] among other things. Many studies regarding the precise fitting [5], low failure rates [14, 
$15,17]$ and few complications [17], confirm the usage of $\mathrm{Co}-\mathrm{Cr}$ alloy for RDPs. Especially double crown systems, consisting of a cemented primary crown on the abutment tooth and a precisely fitted secondary crown as the removable part $[12,16]$ have been established [12] since reliable retention forces got verified [18]. Among other things, the retention forces are influenced by the taper angle as well as the fitting of the secondary crown [13].

To achieve a highly precise fitting, a secondary gold crown could be created by the common process of electro-forming [11]. The direct production of the electro-formed secondary crown on the primary crown optimizes the fitting and eliminates hand-made post processing [6]. While examining galvano-ceramic crowns, it was proven that they can be used alternatively to metal ceramic crowns [11]. Former studies, examining galvano-formed copings on RPDs, mentioned the differences of retention forces between galvano-forming and casting techniques $[6,13,16,19,20]$.

The influence of the taper angle of double crowns has already been examined $[6,13,19-23]$. Obkawa et al., mentioned a $2^{\circ}$ taper angle to be used as a maximum angle for double crown systems in the long-term clinical use [23].

The aim of the study presented as follows was to examine the influence of $0^{\circ}, 1^{\circ}$ and $2^{\circ}$ taper angles as well as the influence of different fabrication methods of the already proven $\mathrm{Co}-\mathrm{Cr}$ alloy. In addition, it was to compare the influence of the high precise fitting of an electroforming secondary crown with the two other fabrication methods, i.e. milling and casting.

The first null hypothesis was that there is no influence of the fabrication method of $\mathrm{Co}-\mathrm{Cr}$ alloy on the retention force regarding the taper. The second null hypothesis was that electroforming a secondary crown does not influence the retention force of double crowns.

\section{Material and Methods}

\section{Production of abutments and primary crowns}

The shape of a first lower molar was used to create 30 metal alloy abutments with lost-wax technique. The metal alloy used (Remanium GM 800+, LOT 936, Dentaurum, GmbH \& Co.KG, Ispringen, Germany, young's modulus $230 \mathrm{GPa}$ ) passed through a manufacturing process. After embedding in investment material (Jet 2000, Lot 1212645, Liquid Type 100, Lot 13061, Siladent, Dr. Böhme \& Schöps, GmbH, Goslar, Germany) and curing for 20 min, the burning process was initialized for $60 \mathrm{~min}$ in an oven (Arca 20, Schütz Dental, GmbH, Rosbach vor der Höhe, Germany) according to the manufacturer's instructions: It included the preheating of the metal alloy $(15 \mathrm{~min})$, followed by the casting process (Globucast, Krupp, AG, Essen, Germany).

The production of the primary crowns started with scanning the metal abutments (Ceramill map 300, Amann Girrbach, AG, Koblach, Austria, Arti Spray, LOT 110, Dr. Jean Bausch, GmbH \& Co.KG, Cologne, Germany), followed by generating 3 different data recordings of the metal abutment. The difference of the data records resulted in 3 different taper angles i.e. $0^{\circ}, 1^{\circ}$ and $2^{\circ}$ (Figure 1). In addition, the data record for $0^{\circ}$ presented a chamfer, which was in contrast to the tangential ending of the data records of $1^{\circ}$ and $2^{\circ}$. Finally 30 primary crowns ( $n=10$ with $0^{\circ}$ taper angle, $\mathrm{n}=10$ with $1^{\circ}$ taper angle, $\mathrm{n}=10$ with $2^{\circ}$ taper angle) were milled out of a chalky blank made of cobalt-chromium (Ceramill Sintron 7116 millimeter, LOT 1303045, Amann Girrbach, AG, Koblach, Austria, Ceramill Motion 2, Amann Girrbach, AG, Koblach, Austria; Figure 2). The chalky primary crowns were sintered (Ceramill Argotherm, Amann Girrbach, AG, Koblach, Austria) with argon (1bar) as part of the inert gas atmosphere using the advised sinter program number 1 which in return uses autonomous heating and cooling rates.

Figure 1. Primary crowns with three different taper angles.
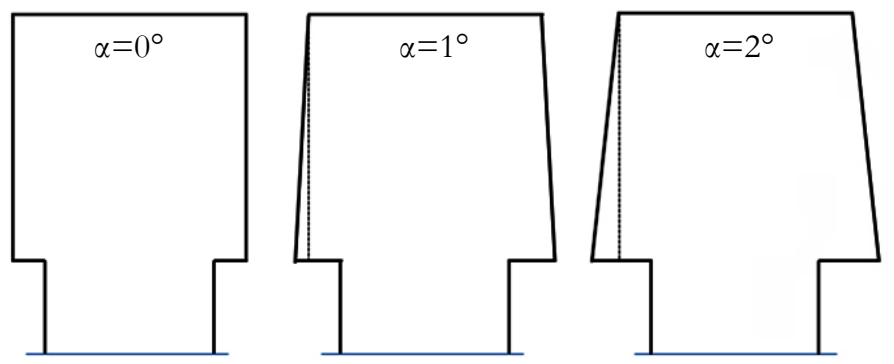

Figure 2. Milled primary crowns in the chalky blank of the Co-Cr material.

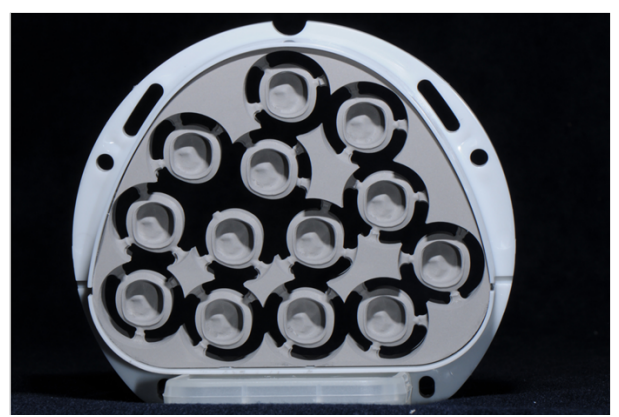


Having air-abraded the inner surface of the primary crowns with alumina particles with a mean particle size of $110 \mu \mathrm{m}$ (basic Quattro IS, Renfert, GmbH, Hilzingen, Germany, Korox 110, LOT 14878430513, Bego, GmbH \& Co.KG, Bremen, Germany), the bonding on the abutments occurred using a self-adhesive resin cement (Rely X Unicem 2, LOT 509981, 3M ESPE, AG, Neuss, Germany). The abutments were loaded afterwards with $150 \mathrm{~g}$ for $10 \mathrm{~min}$ and stored in distilled water at a temperature of $37^{\circ} \mathrm{C}$ for 24h.

The final taper angle and high gloss polishing were given to the primary crowns with a high precise milling process using a watercooled hand held device (W\&H Perfecta 900, W\&H, GmbH, Bürmoos, Austria) fixed in a parallelometer (F4 basic, SN 40024231, Degu Dent, GmbH, Hanau, Germany). The abutments, together with the cemented primary crowns, were later on plastered in a gypsum base (Hera Octastone CN, LOT 3252822, Heraeus Holding, GmbH, Hanau, Germany) to define parallel insertion paths for the pull-off tests.

As a result, 30 high-gloss polished and precisely tapered primary crowns ( $\mathrm{n}=10$ for each taper) cemented on their abutments were used for the production of secondary crowns.

\section{Production of secondary crowns and pull-off tests}

For the production of the secondary crowns, each of the primary crowns was individually scanned (Ceramill map 300, Amann Girrbach, AG, Koblach, Austria, Arti Spray, LOT 110, Dr. Jean Bausch, GmbH \& Co.KG, Cologne, Germany) and a new data record for the secondary crowns was created (Ceramill Mind 2.3.0, Amann Girrbach, AG, Koblach, Austria). All design parameters were optimized to fit between the primary and secondary crown in order to minimize the handmade post-processing errors. The design of the secondary crowns considered a roof ridge with a hole to connect the secondary crowns with the extractor device (Figure 3). The pull-off tests were performed in the pull-off device (Zwick 1445, Zwick, GmbH \& Co.KG, Ulm, Germany) in which the abutments in its gypsum base were fixed and weighted with $50 \mathrm{~N}$ for $20 \mathrm{sec}$. Clinical mimicking conditions were induced by using artificial saliva (Glandosane, No 9235461109, cell pharm, GmbH, Bad Vilbel, Germany). A load of 0.1 Newton and a pulloff speed of $50 \mathrm{~mm} / \mathrm{min}$ were adjusted to execute 20 pull-offs for each secondary crown. Between each test series, microscopic examinations (Stemi DV4 SPOT enlargement of 1.6, Carl Zeiss, AG, Oberkochen, Germany) and re-polishings of the surfaces of the primary crowns were performed.

Milled: The milling process (Ceramill Motion 2, Amann Girrbach, AG, Koblach, Austria) was executed with the appropri- ate driller (Ceramill Roto Motion 0.6 LOT 20120315, 1.0 LOT 20120605, 2.5 LOT 2010605, Amann Girrbach, AG, Koblach, Austria) and the milling strategy as set by the manufacturer. As a result, 30 secondary crowns (10 of each taper angle group) were dryly milled of a chalky blank, i.e. the "green impact" (Ceramill Sintron R 71 L 20 mm, LOT 1402005, Amann Girrbach, AG, Koblach, Austria) and sintered similarly to the primary crowns mentioned above. The sintered secondary crowns were air-abraded (basic Quattro IS, Renfert, GmbH, Hilzingen, Germany) with alumina particles with a mean particle size of $110 \mu \mathrm{m}$ (Korox 110, LOT 14878430513, Bego GmbH \& Co.KG, Bremen, Germany) for $10 \mathrm{sec}$. After providing a precise fit for the secondary crowns using cross burs, they were polished to high-gloss (Abraso-Starglanz asg, REF: 52000163, bredent, Senden, Germany) and pulloff tests were performed as mentioned above.

Cast: For the casting process another 30 crowns were used (10 of each taper angle group) which were milled of wax (brecam. wax 98x20, LOT 382697, bredent, GmbH \& Co.KG, Senden, Germany, Zenotec 4030m1, Wieland Dental, GmbH, Pforzheim, Germany). Six pieces of a kind were embedded in investment material on the associated mold. A spacer made of fleece was yielded into the mold to compensate the expansion of the investment material (Jet 2000, Liquid Type 100, Siladent, Dr. Böhme \& Schöps, GmbH, Goslar, Germany, Lot 1212645, Lot 13061). The curing time lasted $20 \mathrm{~min}$, followed by $60 \mathrm{~min}$ of burning time. The metal alloy (Remanium GM 800+, LOT 936, Dentaurum, GmbH \& Co.KG, Ispringen, Germany; young's modulus $230 \mathrm{GPa}$ ) was preheated (Arca 20,Schütz Dental, GmbH, Rosbach vor der Höhe, Germany) and the casting process occurred in the casting centrifuge (Globucast; Krupp, AG, Essen, Germany). Having removed the investment material, the cooled secondary crowns were air-abraded and fitted to the primary crowns like the milled ones. Then the pull-off test occurred as described before.

Electroforming: Precisely tapered and high-gloss polished, detached primary crowns were air-abraded (basic Quattro IS, Renfert, GmbH, Hilzingen, Germany; Korox 110, LOT 14878430513 , Bego GmbH \& Co.KG, Bremen, Germany) and steam jet cleaned at the inner surfaces. Then, polyurethane resin (Helioform Polyurethane material compound A\&B, LOT 512, C. Hafner, GmbH \& Co.KG, Pforzheim, Germany) was filled in the inside of the primary crowns. The central basal borehole made with a twist driller $(0.9 \mathrm{~mm})$ ensured the contact between the copper anode and the primary crown. A copper pole was stuck in the borehole with instant glue (Uhu, GmbH \& Co.KG, Bühl, Germany) and finally the primary crowns were cleaned with ethanol $(96 \%)$. The silver conductive lacquer (Helioform silver conductive spacer for airbrush, LOT 02/13, C. Hafner, GmbH \& Co.KG, Pforzheim, Germany) was sprayed on the outer surface of the primary crowns

Figure 3. Secondary crown including the hook on top of its primary crown.

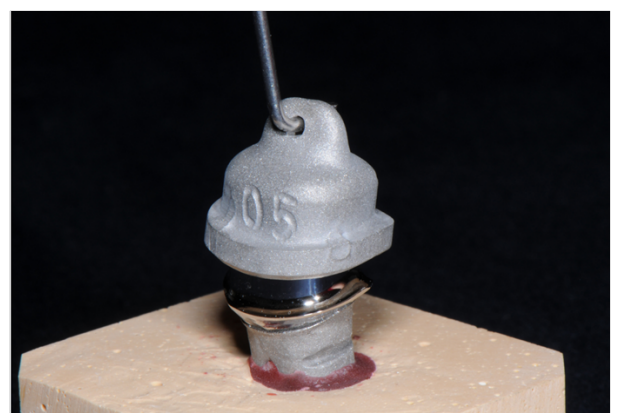


by air-brushing to ensure a steady fine layer. This procedure occurred twice with 0.7 bar, a time gap of $10 \mathrm{~min}$ and distance of $4 \mathrm{~cm}$ between the brush-gun and the crown. In order to ensure a continuous current flow, the linking lane was made by a paintbrush and the related lacquer (Helioform silver conductive spacer, LOT 02/13, C. Hafner, GmbH \& Co.KG, Pforzheim, Germany) was dried for $30 \mathrm{~min}$. Afterwards, the applied light-curing cover lacquer (Helioform cover varnish LC, LOT 122574, C. Hafner, GmbH \& Co.KG, Pforzheim, Germany) limited the area for the galvano formed coping.

The prepared primary crowns on their copper pole were placed in the galvanic device (Hafner HF Vario Plus, C. Hafner GmbH \& Co.KG, Pforzheim, Germany) and the galvanic procedure was initiated in the electroforming bath (Helioform H electrolyte, LOT 00433724, C. Hafner, GmbH \& Co.KG, Pforzheim, Germany, Helioform H concentrate, LOT 0043468, C. Hafner, GmbH \& Co.KG, Pforzheim, Germany) with $17 \mathrm{~mA}$ per crown for $14 \mathrm{~h}$.

The finished crowns, illustrated in Figure 4, were set off the galvanic bath and the galvano formed coping were removed from their primary crowns. Nitric acid (53\%) solved the silver conductive lacquer (Helioform silver conductive spacer for air brush, LOT 02/13, C. Hafner, GmbH \& Co.KG, Pforzheim, Germany) from the galvano formed copings. As a result 30 galvano formed copings, i.e. 10 for each taper angle were produced (Helioform $\mathrm{H}$ concentrate, LOT 0043468, C. Hafner, GmbH \& Co.KG, Pforzheim, Germany). To perform the pull-off test and for stabilizing purposes, the galvano copings were fixed (AGC Cem Automix system, LOT 697720, Wieland Dental GmbH \& Co.KG, Pforzheim, Germany) in a superstructure similar to the design of the other secondary crowns as mentioned above.

\section{Statistical analysis}

Mean, standard deviation (SD) and 95\% confidence interval (CI) were calculated for each test group separately. Verification of data normality was accomplished using the Kolmogorov-Smirnov test. The differences between the tested groups were analyzed with 2-way and 1-way ANOVA, followed by the post-hoc Scheffé test. All statistical analyses were done with IBM SPSS (Version 22; IBM Corporation) and the significance level of $p<0.05$.

\section{Results}

The data of all nine tested groups were normally distributed. Therefore, parametric statistics were performed for the data analysis.

Considering the taper angle, Co-Cr milled $(p=0.077)$ and cast groups $(p=0.106)$ showed no impact on the retention force. In contrast, within the electroforming group, primary crowns with a taper angle of $1^{\circ}$ showed significantly higher retention forces as compared to crowns with $0^{\circ}$ or $2^{\circ}$ angles $(p<0.001)$.

With respect to the secondary crown, a $1^{\circ}$ taper $(p=0.736)$ had no impact. The $0^{\circ}(p<0.001)$ and $2^{\circ}(p=0.002)$ taper angle groups as presented in the electroforming group, displayed significantly lower retention forces as compared to the cast and milled group. In addition, within $0^{\circ}$ taper angle group, milled secondary crowns showed significantly higher values than cast ones.

\section{Discussion}

This study elaborated the different retention forces of a double crown system produced by two different fabrication methods made of $\mathrm{Co}-\mathrm{Cr}$ alloy considering three different taper angles, namely $0^{\circ}, 1^{\circ}$ and $2^{\circ}$. Besides, electroformed secondary crowns were examined and compared to a milled and cast group.

The first null hypothesis was rejected because there was a significant difference between the different fabrication methods in the observation of one taper angle group i.e. the $0^{\circ}$ taper angle with the highest retention force values of the milled secondary crowns. Within the milled and cast group, no influence of the taper angle was proved, although a previous study mentioned the decrease of retention forces with increasing taper angle [22]. However, our study confirmed the result of a former study, which also showed almost no differences of retention forces in the range of $0^{\circ}$ and $2^{\circ}$ [24]. The similar trend of both fabrication methods, milling and casting Co-Cr alloy, has already been examined considering the fracture load of FDPs, showing no significant difference between milled and sintered and conventionally cast frameworks [7]. This trend seems to be in agreement to the retention forces measured in the present study and confirmed by the fact that the influence

Figure 4. Primary crowns prepared for the electroforming process and already electroformed.

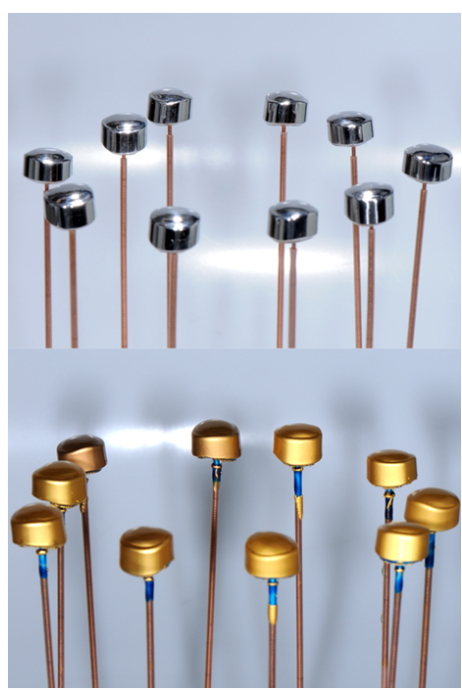


Table 1. Descriptive statistics of retention force including parametric analysis with mean value (Mean) with standard deviation (SD), 95\% confidence intervals $(95 \% \mathrm{CI})$.

\begin{tabular}{|c|c|c|}
\hline Test groups & Mean \pm SD & $95 \%$ CI \\
\hline \multicolumn{3}{|c|}{ Taper angle: $0^{\circ}$} \\
\hline CoCr milled & $28.46 \pm 13.04^{\mathrm{a} / \mathrm{C}}$ & $(19.0 ; 37.8)$ \\
\hline CoCr cast & $14.10 \pm 7.57^{\mathrm{a} / \mathrm{B}}$ & $(8.5 ; 19.6)$ \\
\hline CoCr + electroforming & $2.87 \pm 1.58^{\mathrm{a} / \mathrm{A}}$ & $(1.6 ; 4.0)$ \\
\hline \multicolumn{3}{|c|}{ Taper angle: $1^{\circ}$} \\
\hline CoCr milled & $18.68 \pm 8.86^{\mathrm{a} / \mathrm{A}}$ & $(12.2 ; 25.1)$ \\
\hline CoCr cast & $18.33 \pm 10.33^{\mathrm{a} / \mathrm{A}}$ & $(10.8 ; 25.8)$ \\
\hline CoCr + electroforming & $15.67 \pm 8.78^{\mathrm{b} / \mathrm{A}}$ & $(9.2 ; 22.0)$ \\
\hline \multicolumn{3}{|c|}{ Taper angle: $2^{\circ}$} \\
\hline CoCr milled & $17.40 \pm 11.85^{\mathrm{a} / \mathrm{B}}$ & $(8.8 ; 25.9)$ \\
\hline CoCr cast & $22.77 \pm 8.18^{\mathrm{a} / \mathrm{B}}$ & $(16.8 ; 28.7)$ \\
\hline CoCr + electroforming & $6.56 \pm 6.53^{\mathrm{a} / \mathrm{A}}$ & $(1.7 ; 11.3)$ \\
\hline \multicolumn{3}{|c|}{ All values in Newton $(\mathrm{N})$} \\
\hline
\end{tabular}

a,b: differences between the parallel and cone crowns within one manufacturing method, separately

A,B,C: differences between the material group within parallel and cone crowns, separately

of taper angle exceeded the influence of the fabrication method [6]. Only within the $0^{\circ}$ taper angle group, a significant difference between the milled and cast secondary crown was apparent. Beueret al., [19] mentioned a negative impact on the retention force due to the chamfer design, which was necessary on the one hand to enable adequate adhesion and to limit, on the other hand, apical positioning. Compared to the milled secondary crowns, the extended hand-made fitting process of the cast secondary crowns, executed by a dental technician, influenced the retention force [6, 25]. The chamfer design and the hand-made fitting process seems to have a greater influence on the retention force of $0^{\circ}$ taper angle double crowns than the manufacturing process per se.

The second null hypothesis was also rejected, because the electroformed secondary crowns of $1^{\circ}$ showed significantly higher retention forces than those of $0^{\circ}$ and $2^{\circ}$. The electroformed double crown systems- as investigated in literature - showed different values of retention forces both higher [26] and lower [27] compared to non-electroplated crowns. There in, the electroplated secondary crowns on their cast primary crowns with a taper angle of $2^{\circ}$ showed lower retention force values than the cast secondary gold crowns on their cast primary crowns. This fact reversed in the study just mentioned with in the taper angle groups of $4^{\circ}$ and $6^{\circ}$ [6], which Türp et al., [25] only partially confirmed. In their the investigated double crown systems consisted of gold alloy primary crowns with electroformed gold secondary crowns, zirconia primary crowns with electroformed gold secondary crowns and zirconia primary crowns with cast secondary crowns of nonprecious alloy. Their system showed decreasing retention force values with an increased taper angle from $2^{\circ}$ to $4^{\circ}$, up to $6^{\circ}[25]$. However, the retention force values achieved with electroplated secondary crowns were still sufficient and reproducible [20, 26]. Additional parameters such as the viscosity of the used saliva, the chamfer design and details during the manufacturing process of electroplating influences the retention force $[6,19,20]$.

Due to the apparently missing protocol for investigating double crown systems-especially preload and pull-off speed-the experimental setup for the pull-off tests in the present study corre- sponds to former investigations. The preload of $50 \mathrm{~N}$ is recommended because there is no change on the retention force after raising the preload more than $50 \mathrm{~N}$ [23]. The retention force values of electroplated double crowns showed no dependence on the preload in range of $5 \mathrm{~N}$ to $400 \mathrm{~N}$ [28]. In order to achieve comparable values in all groups, the electroforming secondary crowns in this study were also preloaded with $50 \mathrm{~N}$. The pull-off speed of $50 \mathrm{~mm} / \mathrm{min}$ represents a compromise between the clinical relevance and realizable technical settings.

This study still contained some limitations concerning the overall oral setting and environment. As mentioned above, the retention force values had to be changed by many different influences, e.g. cyclic fatigue loading and the wet environment. No fatigue testing was conducted and the double crown systems underwent no thermo-mechanical loading, which was certainly a short coming of our investigation. Nevertheless, the investigations of retention forces of the newly pre-sintered Co-Cr material and its new fabrication method - with milling and later sintering-showed no disadvantage in comparison to conventional cast double crowns and even electroforming secondary crowns. Further investigations regarding fatigue testing and thermo-mechanical loading will be beneficial to recognize long term trends and are warranted, especially with the taper angle range under investigation ranging from $0^{\circ}$ to $2^{\circ}$, which are recommended for clinical usage.

\section{Conclusion}

Double crowns, produced with new fabrication methods for CoCr materials, e.g. milling under dry conditions and later sintering, showed reliable values considering retention forces in comparison to conventional cast secondary crowns and electroforming secondary crowns. The retention force values of the electroformed secondary crowns confirmed their clinical use for conical crowns as well as telescoping crowns. However, further investigations regarding fatigue testing and thermo-mechanical loading will be beneficial to recognize long term tendency of the new Co-Cr fabrication method. 


\section{Acknowledgement}

The authors would like to express thanks to Amann Girrbach for providing the Sintron blanks, as well as C. Hafner for providing the equipment and material for the electroforming process. All enabled by the financial support of bredent.

\section{References}

[1]. Wataha JC (2002) Alloys for prosthodontic restorations. J Prosthet Dent 87(4): 351-363.

[2]. Suleiman SH, Vult von Steyern P (2013) Fracture strength of porcelain fused to metal crowns made of cast, milled or laser-sintered cobalt-chromium. Acta Odontologica Scandinavica, 71(5): 1280-1289.

[3]. Ohida M, Yoda K, Nomura N, Hanawa T, Igarashi Y (2010) Evaluation of the static frictional coefficients of $\mathrm{Co}-\mathrm{Cr}$ and gold alloys for cone crown telescope denture retainer applications. Dent Mater J 29(6): 706-712.

[4]. Viennot S, Dalard F, Lissac M, Grosgogeat B (2005) Corrosionresistance of cobalt-chromium and palladium-silver alloys used in fixed prosthetic restorations. Eur J Oral Sci 113(1): 90-95.

[5]. Eliasson A, Arnelund CF, Johansson A (2007) Aclinicalevaluation of cobaltchromium metal-ceramic fixed partial dentures and crowns: A three- to seven-year retrospective study. J Prosthet Dent 98(1): 6-16.

[6]. Pietruski JK, Sajewicz E, Sudnik J, Pietruska MD (2013) Retention force assessment in conical crowns in different material combinations. Acta Bioeng Biomech 15(1): 35-42.

[7]. Krug KP, Knauber AW, Nothdurft FP (2015) Fracture behavior of metalceramic fixed dental prostheses with frameworks from cast or a newly developed sintered cobalt-chromium alloy. Clin Oral Investig 19: 401-411.

[8]. Besimo C, Graber G, FlüherM (1996) Retention force changes in implantsupported titanium telescope crowns over long-term use in vitro. J Oral Rehabil 23(6): 372-378

[9]. Brawek PK, Wolfart S, Endres L, Kirsten A, Reich S (2013) The clinicalaccuracy of single crowns exclusively fabricated by digital workflow--the comparison of two systems. Clin Oral Investig 17(9): 2119-2125.

[10]. Tannous F, Steiner M, Shahin R, Kern M (2012) Retentive forces and fatigue resistance of thermoplastic resin clasps. Dent Mater 28(3): 273-278.

[11]. Naumann M, Ernst J, Reich S, Weißhaupt P, Beuer F (2011) Galvano- vs. metal-ceramiccrowns: up to 5-year results of a randomised split-mouth study. Clin Oral Investig 15(5): 657-660.

[12]. Schwindling FS, Dittmann B, Rammelsberg P (2014) Double-crownretained removable dental prostheses: a retrospective study of survival and complications. J Prosthet Dent 112(3): 488-493.

[13]. Özyemiscci-Cebeci N, Yavuzyilmaz H (2013) Comparison of the effects of friction varnish and electroforming on the retention of telescopic crowns. J Prosthet Dent 109(6): 392-396.
[14]. Bernhart G, Koob A, Schmitter M, Gabbert O, Stober T, et al. (2012) Clinical success of implant-supported and tooth-implant-supported double crown-retained dentures. Clin Oral Investig 16(4): 1031-1037.

[15]. Behr M, Hofmann E, Rosentritt M, Lang R, Handel G (2000) Technical failure rates of double crown-retained removable partial dentures. Clin Oral Investig 4(2): 87-90.

[16]. Gurbulak AG, Kilic K, Eroğlu Z, Gercekcioglu E, Kesim B (2013) Evaluation of the retention force of double conical crowns used in combination with a galvano forming and casting fabrication technique. J Prosthodont 22(1): 63-68.

[17]. Svanborg P, Längström L, Lundh RM, Bjerkstig G, Ortorp A (2013) A 5-year restrospective study of cobalt-chronium-based fixed dental prostheses. Int J Prosthodont 26: 343-349.

[18]. Bayer S, Stark H, Gölz L, Keilig L, Kraus D, et al. (2012) Clinical retention force development of double crowns. Clin Oral Investig 16(2): 407-411.

[19]. Beuer F, Edelhoff D, Gernet W, Naumann M (2010) Parameter saffecting retentive force of electroformed double-crown systems. Clin Oral Invest 14(2): 129-135.

[20]. Bayer S, Zuziak W, Kraus D, Keilig L, Stark H, et al. (2011) Conical crowns with electroplated gold copings: retention force changes caused by wear and combined off-axial load. Clin Oral Implants Res 22(3): 323-329.

[21]. Sakai Y, Takahashi H, Iwasaki N, Igarashi Y (2011) Effect of surface roughness and tapered angel of cone crown telescopic system on retention force. Dent Mater J 30(5): 635-641.

[22]. Güngör MA, Artunç C, Sonugelen M (2004) Parameters affecting retentive force of conus crowns. J Oral Rehabil 31(3): 271-277.

[23]. Ohkawa S, Okane H, Nagasawa T, Tsuru H (1990) Changes in retention of various telescope crown assemblies over long-term use. J Prosthet Dent 64(2): 153-158.

[24]. Dillschneider T, Nothdurft FP, Abed-Rabbo M, Mitov G, Pospiech PR (2009) In vitro-investigations on the wear behavior of different double crown systems. Dent Mater 25: e20.

[25]. Turp I, Bozdağ E, Sünbüloğlu E, Kahruman C, Yusufoğlu I, et al. (2014) Retention and surface changes of zirconia primary crowns with secondary crowns of different materials. Clin Oral Investig 18(8): 2023-2035.

[26]. Bayer S, Kraus D, Keilig L, Gölz L, Stark H, et al. (2012) Wear of double crown systems: electroplated vs. casted female part. J Appl Oral Sci 20(3): 384-391.

[27]. Engels J, Schubert O, Güth JF, Hoffmann M, Jauernig C, et al. (2013) Wear behavior of different double-crown systems. Clin Oral Investig 17(2): 503510.

[28]. Weigl P, Hahn L, Lauer HC (2000) Advanced biomaterials used for a new telescopic retainer for removable dentures. J Biomed Mater Res 53(4): 320 336. 